\title{
PENGARUH UKURAN DIAMETER LUBANG DALAM ARAH MEMANJANG TERHADAP KEKUATAN TEKAN BENDA UJI SILINDER BETON
}

\author{
Helwiyah Zain ${ }^{1}$ \\ ${ }^{1)}$ Program Studi Teknik Sipil Universitas Abulyatama \\ Jl. Blang Bintang Lama Km. 8,5 Lampoh Keudee Aceh Besar \\ email: ocudma2h@gmail.com
}

\begin{abstract}
Design of buildings should pay attention to aspects; Strength, comfort, economics, and aesthetics. One aspect of the aesthetic that is often seen is the rain water pipeline from the roof to the channel on the ground. In order for this pipe is not be seen from the outside, it can be done by aasembling into thecore of the column so that it looks beautiful. To know the effect of hole in the column, need to do research. The aim of this research is to find out the influence of the variation of the size of the longitudinal aperture in the cylindrical specimen against the compressive strength of the concrete. The number of specimen were 20 pieces, consisting of 15 pieces of specimens given pipe holes and 5 pieces are not given a hole (intact). Variations of hole size, namely: $2.5 \mathrm{~cm}, 5 \mathrm{~cm}$ and $7.5 \mathrm{~cm}$. Each variation of hole size of specimen 5 pieces. Concrete mixture design is done based on ACI method. The specimens used in this research are cylindrical shape specimens with diameter $15 \mathrm{~cm}$ and height $30 \mathrm{~cm}$. Testing of concrete compression done at age 28 days. The test of the specimen is carried out by giving the compression load slowly until the specimen failured. The test results obtained the compressive strength of the specimen without hole $=266.48 \mathrm{~kg} / \mathrm{cm}^{2} ;$ specimen with hole diameter $2.5 \mathrm{~cm}=243,08 \mathrm{~kg} / \mathrm{cm}^{2}$; specimen with hole diameter $5 \mathrm{~cm}=226,22 \mathrm{~kg} / \mathrm{cm}^{2}$; and specimen with hole diameter $7.5 \mathrm{~cm}=190,13 \mathrm{~kg} / \mathrm{cm}^{2}$. The results of this experiments show that the specimen with diameter of hole $2.5 \mathrm{~cm}$ is $91 \%$ of the specimen without hole, the specimen with hole diameter $5 \mathrm{~cm}$ is $85 \%$ of the specimen without hole; and the specimen with hole diameter $7.5 \mathrm{~cm}$ is $71 \%$ of the specimen without hole. The results of this experimen show that the larger size of the hole in the column the smaller the compressive strength of the concrete compared to the specimen without holes.
\end{abstract}

Keywords: hole diameter size, testing, compressive strength.

\begin{abstract}
Abstrak: Perencanaan bangunan gedung harus memperhatikan aspek; kekuatan, kenyamanan, ekonomis, dan estetika. Salah satu aspek estetika yang sering terlihat adalah pipa penyaluran air hujan dari atap sampai ke saluran pembuan di tanah. Agar pipa ini tidak terlihat ke luar, dapat dilakukan dengan cara menanam ke dalam tiang (kolom) sehingga tiang terlihat asri. Untuk mengetahui pengaruh kekuatan tiang yang ditanam pipa di dalamnya, perlu dilakukan penelitian. Penelitian yang dilakukan bertujuan untuk mengetahui pengaruh variasi ukuran lubang arah memanjang dalam benda uji silinder terhadap kekuatan tekan beton. Jumlah benda uji sebanyak 20 buah, terdiri dari 15 buah benda uji diberi lubang pipa dan 5 buah tidak diberi lubang (utuh). Variasi ukuran lubang disesuaikan dengan ukuran diameter pipa yang tersedia, yaitu: $2,5 \mathrm{~cm}, 5 \mathrm{~cm}$ dan 7,5 cm. Masing-masing variasi ukuran lubang jumlah benda uji 5 buah. Perencanaan campuran beton dikerjakan berdasarkan metode ACI. Benda uji yang digunakan pada penelitian ini adalah benda uji silinder dengan diameter $15 \mathrm{~cm}$ dan tinggi $30 \mathrm{~cm}$. Pengujian tekan beton dilakukan pada umur 28 hari. Pengujian terhadap benda uji dilakukan dengan memberikan beban tekan secara perlahan-lahan sampai benda uji hancur. Hasil pengujian diperoleh kuat tekan rata-rata benda uji utuh (tanpa lubang) $=266,48 \mathrm{~kg} / \mathrm{cm}^{2}$; benda uji dengan diameter lubang $2,5 \mathrm{~cm}=243,08 \mathrm{~kg} / \mathrm{cm}^{2}$; benda uji dengan diameter lubang $5 \mathrm{~cm}=226,22$ $\mathrm{kg} / \mathrm{cm}^{2}$; dan benda uji dengan diameter lubang $7,5 \mathrm{~cm}=190,13 \mathrm{~kg} / \mathrm{cm} 2$. Hasil evaluasi dari percobaan menunjukkan bahwa pada benda uji yang diameter lubangnya 2,5 cm adalah 91\% dari benda uji utuh, benda uji yang diameter lubangnya $5 \mathrm{~cm}$ adalah $85 \%$ dari benda uji utuh; dan benda uji yang diameter lubangnya $7,5 \mathrm{~cm}$ adalah $71 \%$ dari benda uji utuh. Hasil pengujian ini
\end{abstract}


menunjukkan bahwa semakin besar ukuran lubang dalam kolom semakin kecil kekuatan tekan beton dibandingkan terhadap benda uji tanpa lubang.

\section{Kata Kunci : ukuran diameter lubang, pengujian, kekuatan tekan.}

Bangunan gedung bertingkat harus dirancang sedemikian rupa memenuhi aspek kekuatan, kenyamanan, ekonomis dan yang tidak kalah penting adalah aspek estetika (enak dipandang). Aspek estetika menjadi bobot penilaian dalam menentukan disain sebuah gedung. Banyak faktor yang menunjang estetika sebuah gedung, antara lain; bentuk gedung, warna, serta assoseris yang digunakan pada gedung tersebut. Salah satu assoseris yang sering dijumpai pada bangunan adalah lintasan saluran pembuang air hujan dari atap sampai ke tanah. Lintasan ini dapat dilakukan dengan memasang pipa sebelah luar menempel pada kolom atau dimasukkan ke dalam kolom. Cara kedua ini terlihat lebih disukai karena kolom terlihat lebih bersih.

Kolom pada bangunan gedung fungsi utamanya adalah untuk mendukung beban dari atas selanjutnya diteruskan ke pondasi. Kolom yang menyalurkan pipa pembuangan air hujan di bagian dalam menyebabkan penurunan kapasitas kolom dalam memikul beban.

Tujuan dari penelitian ini adalah untuk mengetahui pengaruh variasi ukuran lubang dalam arah memanjang kolom terhadap kekuatan kolom yang diuji di Laboratorium. Dalam penelitian ini, kolom dibuat bentuk silinder standar benda uji, dan lubang dalam silinder bervariasi ukuran diameternya yaitu: $2,5 \mathrm{~cm}) ; 5,00 \mathrm{~cm}$ dan $7,5 \mathrm{~cm}$.

\section{KAJIAN PUSTAKA}

Agregat halus dan kasar sebagai bahan susun kasar campuran merupakan komponen utama beton. Nilai kekuatan serta daya tahan (durability) beton merupakan fungsi dari banyak faktor, diantaranya adalah nilai banding campuran dan mutu bahan susun, metode pelaksanaan pengecoran, pelaksanaan finishing, temperatur dan kondisi perawatan pengerasannya.

\section{Faktor Air Semen (FAS)}

Faktor air semen (FAS) adalah perbandingan antara berat air dan berat semen.

$\mathrm{FAS}=\frac{\text { berat air }}{\text { berat semen }}$

Mulyono (2005) menyatakan, air diperlukan pada pembuatan beton untuk memicu proses kimiawi semen, membasahi agregat, dan memberikan kemudahan dalam pekerjaan beton (workability). Untuk air yang terlalu sedikit menyebabkan proses hidrasi tidak tercapai seluruhnya sehingga akan mempengaruhi kekuatan beton, oleh karena itu perbandingan air dengan semen (faktor air semen) menjadi penting.

Murdock (1999) berpendapat bahwa untuk semua tujuan, beton yang mempunyai faktor air semen minimal dan cukup untuk 
memberikan workabilitas tertentu yang dibutuhkan untuk pemadatan yang sempurna tanpa pekerjaan pemadatan yang berlebihan, merupakan beton yang terbaik.

\section{Sifat-Sifat Fisis Agregat}

Agregat berfungsi sebagai bahan pengisi, tetapi peranannya dalam menentukan kekuatan beton lebih kecil daripada semen. Agregat dengan sifat kekerasan, kepadatan, dan keawetan tinggi mempunyai sifat kekekalan yang baik, sehingga akan menghasilkan beton yang berkualitas tinggi. Pemeriksaan sifat-sifat fisis agregat meliputi pemeriksaan berat jenis (specific gravity), penyerapan (absorbs), berat volume agregat (bulk density), analisa saringan (sieve analysis) agregat, modulus kehalusan (fineness modulus), gradasi agregat, kadar air agregat.

\section{Gradasi agregat}

Gradasi agregat adalah distribusi dari variasi ukuran butir agregat. Gradasi agregat berpengaruh pada besarnya rongga dalam campuran dan menentukan workabilitas (kemudahan dalam pekerjaan) serta stabilitas campuran. Gradasi agregat ditentukan dengan cara analisa saringan, dimana sampel agregat harus melalui satu set saringan. Ukuran saringan menyatakan ukuran bukaan jaringan kawat dan nomor saringan menyatakan banyaknya bukaan jaringan kawat per inchi pesegi dari saringan tersebut, daerah grafik gradasi agregat bisa dilihat pada gambar 1 .

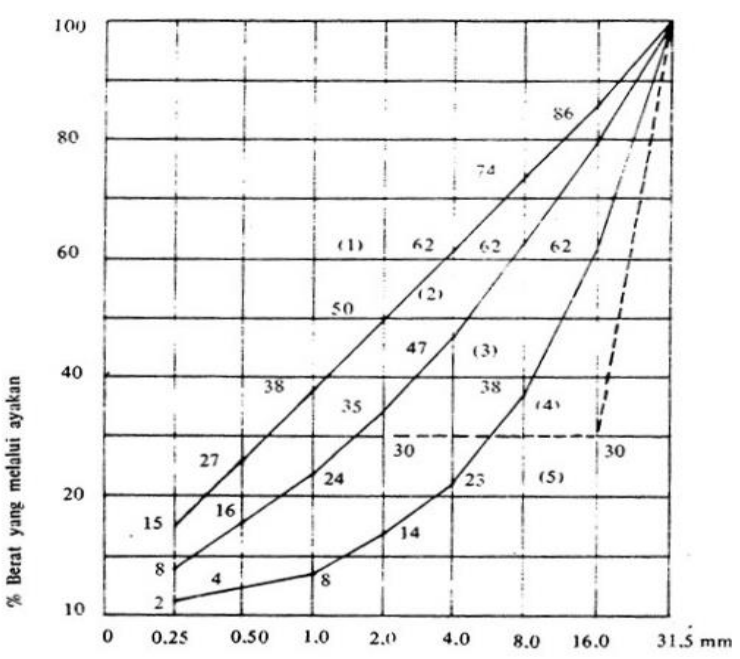

Gambar 1. Grafik daerah susunan butiran untuk agregat campuran dengan diameter maksimum $25,4 \mathrm{~mm}$

Sumber: PBI 1971

Angka-angka dalam kurung pada Gambar 1 mempunyai arti:

(1). Daerah tidak baik, diperlukan banyak semen dan air;

(2). Daerah baik, tetapi diperlukan banyak semen dan air dibandingkan dengan daerah (3);

(3). Daerah baik sekali;

(4). Daerah tidak baik untuk susunan butiran diskontinu;

(5). Daerah sangat tidak baik, terlalu sulit dikerjakan

\section{METODE PENELITIAN}

Penelitian ini menggunakan bahan beton yaitu; semen, agregat (pasir dan kerikil), air dan pipa saluran air hujan. Benda uji yang digunakan berbentuk silinder standar. Jumlah benda uji sebanyak 20 buah yang bervariasi ukuran diameternya. Material beton diaduk hingga merata, dituang ke dalam cetakan benda 
uji, dirawat selama 28 hari. Pengujian terhadap benda uji dilakukan dengan memberikan beban tekan secara perlahan-lahan sampai benda uji hancur.

\section{Material Beton}

Material yang digunakan dalam penelitian ini adalah; semen, agregat (pasir dan kerikil) dan air. Semen buatan pabrik Semen Andalas, diperoleh dari toko bahan bangunan, bahan agregat pasir dan kerikil dari sungai Krueng Aceh, air berasal dari PDAM Kota Banda Aceh. Pipa penyaluran air hujan digunakan merek Wavin, diperoleh dari toko bahan bangunan di Kota Banda Aceh sesuai dengan ukuran yang telah direncanakan. Semen diambil langsung dari pabrik, sehingga tidak dilakukan pemeriksaan laboratorium. Agregat kasar yang digunakan adalah kerikil dengan diameter maksimum 31,5 mm. Agregat kasar diperiksa: sifat-sifat fisis, berat jenis, berat volume, dan analisis saringan. Agregat yang memenuhi syarat, diaduk sampai homogen dan berproses sehingga menjadi beton.

\section{Bentuk dan Jumlah Benda Uji}

Benda uji berupa silinder standar dengan ukuran diameter $15 \mathrm{~cm}$ dan tinggi $30 \mathrm{~cm}$. Jumlah benda uji sebanyak 20 buah, terdiri dari 15 buah benda uji diberi lubang pipa dan 5 buah tidak diberi lubang (utuh). Variasi ukuran lubang disesuaikan dengan ukuran diameter pipa yang tersedia, yaitu: $2,5 \mathrm{~cm}, 5 \mathrm{~cm}$ dan $7,5 \mathrm{~cm}$. Masing-masing variasi ukuran lubang jumlah benda uji 5 buah dan buah 5 buah

\section{Pembuatan benda uji}

benda uji sebagai pembanding dibuat tanpa lubang. Bahan beton diaduk dengan mesin pengaduk (mollen) sehingga merata (homogen). Campuran beton ini dimasukkan ke dalam cetakan silinder dengan urutan 5 buah silinder tanpa lubang, 5 buah silinder ukuran diameter lubang $2,5 \mathrm{~cm}, 5$ buah silinder ukuran diameter lubang $5 \mathrm{~cm}$, dan 5 buah silinder ukuran diameter lubang 7,5 cm. Masingmasing cetakan silinder dipadatkan dengan menggunakan tongkat besi sebanyak 25 kali tusukan. Pada umur 1 hari, mesing-masing benda uji dibuka cetakannya dan diberi kode masing-masing. Benda uji selanjutnya dilakukan proses perawatan.

\section{Perawatan Benda Uji}

Perawatan ini bertujuan untuk menjaga agar terjadi proses pengikatan dan perawatan dapat berlangsung dengan sempurna. Perawatan benda uji dilakukan dengan merendam ke dalam bak perendaman dan disusun dengan rapi dan berurut agar memudahkan pada saat pengambilan. Perawatan dengan cara rendaman ini sampai umur benda uji mencapai 28 hari.

\section{Peralatan Pengujian}

Peralatan yang digunakan pada penelitian ini terdiri dari dua kelompok, yaitu: peralatan untuk pemeriksaan sifat-sifat fisis agregat dan peralat untuk pengujian kuat tekan benda uji. Peralatan yang digunakan untuk pemeriksaan sifat-sifat fisis, terdiri dari peralatan-peralatan kecil yang masing-masing berbeda untuk setiap 
jenis pemeriksaan. Peralatan untuk pengujian kuat tekan benda uji, digunakan mesin uji tekan yang dilengkapi dengan tempat duduk benda uji, torak penekan dan penahan serta alat pencatat beban dan perpendekan benda uji.

\section{Pengujian Benda Uji}

Metode yang digunakan untuk pengujian benda uji silinder adalah metode ASTM (Anonim, 1995). Benda uji yang sudah dikeluarkan dari tempat perendaman (1 hari sebelumnya), dibersihkan dan dikeringkan permukaannya. Pengujian di sini dibagi dalam 4 kelompok benda uji, yaitu: kelompok benda uji tanpa lubang, kelompok benda uji ukuran diameter lubang $2,5 \mathrm{~cm}$, kelompok benda uji ukuran diameter lubang $5 \mathrm{~cm}$, dan kelompok benda uji ukuran diameter lubang $7,5 \mathrm{~cm}$. Satu persatu benda uji diletakkan di bawah torak pembebanan dalam arah vertikal. Torak mesin pembebanan disetel menyentuh permukaan benda uji sebelah atas dan bawah .
Kecepatan pembebanan dimulai dari 2 $\mathrm{kg} / \mathrm{cm}^{2} /$ detik. Pengamatan selama pengujian dilakukan mulai dari beban awal sampai beban akhir (benda uji hancur). Setiap benda uji pada saat hancur dicatat besarnya beban maksimum, pola retak dan pola kehancuran yang terjadi. Data ini dijadikan sebagai informasi pada saat pengolahan data. Demikian seterusnya untuk benda uji yang lain.

\section{HASIL DAN PEMBAHASAN}

Pengujian yang telah dilakukan terhadap pemeriksaan sifat-sifat fisis agregat dan pengujian kekuatan tekan benda uji akan dilaporkan berikut ini.

\section{Pemeriksaan Sifat-sifat Fisis Agregat}

Pemeriksaan sifat-sifat fisis agregat yang dilakukan terhadap material: kerikil, pasir kasar dan pasir halus. Pemeriksaan terhadap material ini meliputi: berat volume (bulk density), berat jenis (spesific gravity), penyerapan (absorbtion), dan modulus kehalusan (fineness modulus) agregat. Hasil pengujian sifat-sifat fisis agregat seperti terlihat pada Tabel 1 .

Tabel 1. Hasil Pengujian Sifat-sifat Fisis Agregat

\begin{tabular}{|c|l|c|c|c|c|c|}
\hline \multirow{2}{*}{ No } & \multirow{2}{*}{ Jenis Agregat } & \multirow{2}{*}{$\begin{array}{c}\text { Berat } \\
\text { Volume }\end{array}$} & \multicolumn{2}{|c|}{ Berat Jenis } & \multirow{2}{*}{ Absorbsi } & $\begin{array}{c}\text { Modulus } \\
\text { Kehalusan }\end{array}$ \\
\cline { 4 - 5 } & & SG ssd & SGod & & 7,101 \\
\hline 1 & Kerikil & 1,751 & 2,65 & 2,6 & 2,16 & 4,62 \\
\hline 2 & Pasir Kasar & 1,746 & 2,06 & 2,02 & 1,81 & 2,932 \\
\hline 3 & Pasir Halus & 1,486 & 2,438 & 2,333 & 4,527 & \\
\hline
\end{tabular}


Menurut Orchard (1979), berat volume agregat minimum 1,445 $\mathrm{kg} /$ liter, menurut Troxell (1968), berat volume agregat kasar > $1,560 \mathrm{~kg} /$ liter dan agregat halus $>1,400 \mathrm{~kg} /$ liter. Oleh karena itu agregat tersebut memenuhi syarat sebagai bahan untuk campuran beton.

Persyaratan untuk berat jenis agregat kasar menurut Troxell (1968), berkisar antara 2,5 2,8 dan untuk agregat halus (pasir kasar dan pasir halus) berkisar antara 2,0 - 2,6. Dengan demikian berarti agregat yang digunakan memenuhi syarat.

Persyaratan absorbsi menurut Troxell (1968) untuk kerikil, antara 0,5\%-1\%, dan untuk pasir kasar antara $0 \%$ - 2\% sedangkan untuk pasir halus antara $0 \%-2 \%$.

Persyaratan untuk modulus kehalusan kerikil, menurut Anonim (1995) berkisar antara 5,5 - 8,0, sedangkan untuk pasir kasar antara 2,9 - 4,2, dan pasir halus berkisar antara 2,2 2,6. Berdasarkan hasil pemeriksaan ini, secara keseluruhan agregat tetap dipakai untuk campuran beton, karena telah merupakan ketentuannya.

\section{Pengujian Kuat Tekan Silinder}

Hasil pengujian kuat tekan silinder beton seperti terlihat pada Tabel 2, di bawah ini.
Tabel 2. Hasil pengujian kuat tekan silinder beton

\begin{tabular}{|c|c|c|c|c|c|}
\hline $\begin{array}{c}\text { Variasi } \\
\text { Diameter } \\
\text { Beton }\end{array}$ & Umur & $\begin{array}{c}\text { Nama } \\
\text { Benda Uji }\end{array}$ & $\begin{array}{c}\text { Luas Benda } \\
\text { Uji }\left(\mathrm{cm}^{2}\right)\end{array}$ & $\begin{array}{c}\text { Beban } \\
(\mathrm{Kg})\end{array}$ & $\begin{array}{c}\text { Kuat Tekan } \\
\left(\mathrm{Kg} / \mathrm{cm}^{2}\right)\end{array}$ \\
\hline \multirow{5}{*}{$\begin{array}{l}\text { Beton Tanpa } \\
\text { Lubang }\end{array}$} & \multirow{3}{*}{$\begin{array}{c}28 \\
\text { hari }\end{array}$} & KN01 & 176,63 & 48950 & 277,13 \\
\hline & & KN02 & 176,63 & 49630 & 280,98 \\
\hline & & KN03 & 176,63 & 47560 & 269,26 \\
\hline & & KN04 & 176,63 & 46000 & 260,43 \\
\hline & & KN05 & 176,63 & 43200 & 244,58 \\
\hline & & \multicolumn{3}{|c|}{$\frac{1}{\text { Rata-rata Kuat Tekan Silinder Beton }}$} & 266,48 \\
\hline \multirow{5}{*}{$\begin{array}{l}\text { Diameter 2,5 } \\
\mathrm{cm}\end{array}$} & \multirow{5}{*}{$\begin{array}{c}28 \\
\text { hari }\end{array}$} & KL101 & 176,63 & 47390 & 268,30 \\
\hline & & KL102 & 176,63 & 42200 & 238,92 \\
\hline & & KL103 & 176,63 & 41110 & 232,75 \\
\hline & & KL104 & 176,63 & 40640 & 230,09 \\
\hline & & KL105 & 176,63 & 43340 & 245,37 \\
\hline & & \multicolumn{3}{|c|}{ Rata-rata Kuat Tekan Silinder Beton } & 243,08 \\
\hline \multirow{5}{*}{ Diameter $5 \mathrm{~cm}$} & \multirow{5}{*}{$\begin{array}{c}28 \\
\text { hari }\end{array}$} & KL201 & 176,63 & 42150 & 238,63 \\
\hline & & KL202 & 176,63 & 40210 & 227,65 \\
\hline & & KL203 & 176,63 & 34980 & 198,04 \\
\hline & & KL204 & 176,63 & 41330 & 233,99 \\
\hline & & KL205 & 176,63 & 41120 & 232,8 \\
\hline & & \multicolumn{3}{|c|}{ Rata-rata Kuat Tekan Silinder Beton } & 226,22 \\
\hline \multirow{5}{*}{$\begin{array}{l}\text { Diameter 7,5 } \\
\mathrm{cm}\end{array}$} & \multirow{5}{*}{$\begin{array}{c}28 \\
\text { hari }\end{array}$} & KL301 & 176,63 & 35600 & 201,55 \\
\hline & & KL302 & 176,63 & 37710 & 213,50 \\
\hline & & KL303 & 176,63 & 33100 & 187,40 \\
\hline & & KL304 & 176,63 & 30800 & 174,38 \\
\hline & & KL305 & 176,63 & 30700 & 173,81 \\
\hline & & \multicolumn{3}{|c|}{$\frac{1}{\text { Rata-rata Kuat Tekan Silinder Beton }}$} & 190,13 \\
\hline
\end{tabular}

Berdasarkan Tabel 2 di atas, kuat tekan rata-rata dari pengujian beton ini, dapat dibuat grafik pengaruh variasi diameter lubang dalam benda uji terhadap kekuatan tekan beton. Adapun grafik tersebut dapat dilihat pada Gambar 2 di bawah ini:

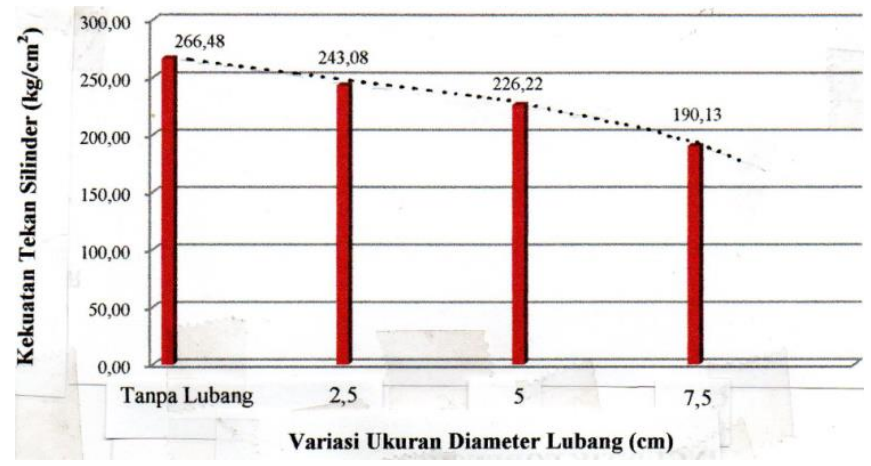

Gambar 2. Hubungan Ukuran lubang dengan kuat tekan beton 
Berdasarkan Gambar 2 diatas dapat dilihat bahwa semakin besar diameter lubang yang digunakan pada benda uji, maka semakin kecil kekuatan tekannya.

Jika dilihat dalam bentuk prosentase, perbandingan nilai penurunan kuat tekan beton berdasarkan variasi ukuran diameter lubang dapat dilihat pada Tabel 3 .

Tabel 3 Penurunan kuat tekan silinder

\begin{tabular}{|c|l|c|c|c|c|}
\hline No & Aspek yang ditinjau & $\begin{array}{r}\text { Tanpa } \\
\text { lubang }\end{array}$ & $\begin{array}{c}\text { Diameter } \\
\text { lubang } \\
\mathbf{2 , 5} \mathbf{~ c m}\end{array}$ & $\begin{array}{c}\text { Diameter } \\
\text { lubang } \\
\mathbf{5} \mathbf{~ c m}\end{array}$ & $\begin{array}{c}\text { Diameter } \\
\text { lubang } \\
\mathbf{7 , 5} \mathbf{~ c m}\end{array}$ \\
\hline 1. & $\begin{array}{l}\text { Kuat tekan benda uji } \\
\text { silinder }\left(\mathrm{kg} / \mathrm{cm}^{2}\right)\end{array}$ & 266,48 & 243,08 & 226,22 & 190,13 \\
\hline 2. & $\begin{array}{l}\text { Perbandingan kuat tekan } \\
\text { terhadap benda uji tanpa } \\
\text { lubang (\%) }\end{array}$ & 100 & 91 & 85 & 71 \\
\hline
\end{tabular}

Berdasarkan Tabel 3 penurunan kekuatan tekan beton akibat variasi ukuran lubang dalam benda uji, baik kekuatan beton langsung $\left(\mathrm{kg} / \mathrm{cm}^{2}\right)$ maupun dalam persen $(\%)$, terlihat bahwa semakin besar diameter lubang yang digunakan pada benda uji, semakin kecil kekuatan silinder beton. Oleh karena itu, dalam pelaksanaan sehari-hari pada setiap kolom yang menggunakan pipa saluran pembuang air hujan yang ditanam dalam kolom, perlu ditambah perkuatan dengan memberi tulangan agar struktur kolom tidak mengalami pengurangan kekuatan.

\section{KESIMPULAN DAN SARAN}

\section{Kesimpulan}

1. Material yang digunakan dalam penelitian ini telah memenuhi syarat sebagai material beton.
2. Semakin besar ukuran lubang dalam arah memanjang kolom akan semakin kecil kekuatan tekannya.

3. Pola penurunan kekuatan benda uji cenderung membentuk garis lengkung (parabola).

\section{Saran}

1. Untuk mendapatkan hasil yang lebih akurat, disarankan penggunaan variasi ukuran diameter lubang yang lebih banyak.

2. Selain dilakukan pada struktur kolom, disarankan bagi peneliti lain, menggunakan struktur jenis lain seperti balok atau pelat.

3. Jika pipa pembuangan ditanam ke dalam kolom, disarankan untuk menambah tulangan untuk menghindari penguarang kekuatan kolom.

\section{DAFTAR PUSTAKA}

Departemen Pekerjaan Umum dan Tenaga Listrik. (1971). Peraturan Beton Bertulang Indonesia NI-2. Jakarta: Departemen Pekerjaan Umum dan Tenaga Listrik.

American Concrete Institute Committee (1977). Recommended Practice for Selecting Proportions for Normal,

Heavyweight, and Mass Concrete. Detroit Michigan American: Concrete Institute Committee (ACI) 211.1-77.

Departemen Pekerjaan Umum dan Bahan Penelitian dan Pengembangan

PU. (1990). SNI-03-1974-1990: 
Jurnal Teknik Sipil Unaya

Metode Pengujian Kuat Tekan Beton.

Jakarta: Departemen Pekerjaan

Umum dan Bahan Penelitian dan

Pengembangan PU.

International Standard-Worldwide. (1995).

Concrete and Aggregates

Detroit Michigan: International

Standard-Worldwide.

Departemen Pekerjaan Umum dan Bahan

Penelitian dan Pengembangan PU. (2002). SNI 03-2835-2002: Syarat

Teknis Bahan Bangunan. Jakarta:

Pusat Penelitian dan Pengembangan

Pemukiman.

Mulyono, T. (2005). Teknologi Beton.

Yogyakarta: Penerbit ANDI.

Murdock, L. J. dan Brooks, K. M.. (1991).

Bahan dan Praktek Beton,

terjemahan Hindarko, S. Jakarta:

Penerbit Erlangga.

Orchard, D.F. (1979). Concrete Technology Applied Science, Vol. 1, London: Applied Science.

Troxell, G.E., et al. (1968). Composition and Properties of Concrete. London: Mac Graw Hill Book Company. 